\title{
Proposal of an interdisciplinary test involving the disciplines of physics, chemistry, geography and biology
}

\begin{abstract}
The present work reports an experience concerning to the development of an interdisciplinary test. The built test has Energy as generator theme, aiming to instigate the reasoning of the student for the main aspects of the relationship between economic development and sustainability. Elaborated by teachers of the areas of Physics, Chemistry, Geography and Biology, the mentioned test was applied for three classes of the second year of the High-School of a public school. The results of the application of the test show that this kind of test represents a viable and dynamics alternative to foment the teaching of sciences. Among the positive impacts of this sort of approach, we highlight the possibility of illustrate for the student a more holistic vision of the scientific process. The success of the application of the test was verified by an analysis of the grades obtained by the students and through a half structured interview, which the student can express their opinions about the test. By mean of such hybrid approach, quantitative and qualitative and exploratory, we confirm the effectiveness of the methodology proposed in this work. In addition, the results generated by this experience has great potential to inspire and motivate teachers to work with generator themes that agglutinate the various areas of the scientific knowledge.
\end{abstract}

Keywords: energy, interdisciplinary teaching, sustainable development, themes, teachers, economic development, classes, scientific knowledge, complementarity, school practices, school environment, school space, classrooms, interdisciplinary practices
Volume 2 Issue 4 - 2018

\author{
Thiago Mello dos Reis, Graziani Mondoni \\ Silva, Rafael Mantovaneli Sousa \\ Instituto Federal do Espírito Santo, Campus Centro-Serrano, \\ Brazil
}

Correspondence: Thiago Mello dos Reis, Instituto Federal do Espírito Santo, Campus Centro-Serrano, Estrada Guilherme João Frederico Kruger, s/n, Santa Maria de Jetibá, ES. CEP: 29645-000, Brazil,Email thiago.mello@ifes.edu.br

Received: July 29, 2018 | Published: August 03, 2018

\section{Introduction}

Interdisciplinarity can be defined as the interaction between two or more subjects such that this interaction can go from the communication of the ideas to the mutual integration of the director concepts of epistemology, terminology, methodology, procedures, data and organization regarding teaching and research. ${ }^{1}$ Traditionally, a student of the secondary school have several segregated classes in which the contents are exposed in isolation among the several disciplines. In this scenario, many contents that are most significantly understood through the complementarity between two or more lines of scientific knowledge are seen by students as isolated entities of certain specific subjects. This context is not desirable because it causes the student not to acquire the integrated vision of the various sciences to form a joint that results in a unified view of the scientific process of understanding reality. Although there are regulations and clearly positive aspects in the practice of interdisciplinarity in science teaching, some difficulties arise in the implementation of the daily application of interdisciplinary methods. Disciplinary epistemological clashes, teacher and students conceptions about the nature of science and school practices, school space-time structure, are some of the most frequent obstacles. ${ }^{2}$ Among the barriers encountered, the teacher assignments in the school environment, which include long times inside the classroom and diverse administrative assignments, are possibly the main current difficulties for existence of a few interdisciplinary practices in schools. Other point that is often related for teachers as circumstances that difficult interdisciplinary actions are the disinterest and the indiscipline of the students. ${ }^{3}$ The approach through daily themes that are explored by the various sciences is a strategy that have a great potential to aid teachers to resolve the main difficulties that are mentioned for the students. A strategy that have great potential to make the students more interested in the school environments is to insert the interdisciplinary activities in the school tests.

The elaboration of tests that involve more of one discipline is not a simple process. The same problems that we mention as impediment factors in the implementation of interdisciplinary practices are also applied to the elaboration of tests and other interdisciplinary evaluative instruments. Problems like these, suggest that there are a systematic crises in the teaching of sciences, that need to be serious and highly reinvented. ${ }^{4}$ An efficient alternative for the teachers of sciences is to see the relationship between the subjects of their disciplines and then to build themes and subjects that dialogue mutually. From a generator or central theme, is possible to elaborate classes and tests that are directed to discussions of the problems associated to this central theme. ${ }^{5}$ In this work we report an experience of application of an interdisciplinary test about Energy, involving the disciplines of Physics, Chemistry, Geography and Biology. Beyond we present the results of application of the test; we expose the process of construction of the referred test. Among the possibilities that arise in this work, we highlight the publication of a test about a theme that have a great daily and scientific relevance, which is ready to be applied and the invitation to other teachers to implement the presented methodology for the elaboration of similar interdisciplinary tests, which involve other themes and disciplines. 


\section{Methodology}

Initially, the team of teachers met in order to define the central theme of the test. The idea of agglutinating several points of the contents of the various involved disciplines to contemplate the subjects to be worked out with the students. The selected theme was Energy since the moment of the year in which the test was applied, the quantity of possible contents to be considered and the theme relevance. During the preliminary discussions, the collective intention raised by the teachers which were part of the elaboration of the test was to provoke discussions between the students so as they could to exercise the capacity of dissertate argumentatively about the contemporaneous subjects and that affect directly and decisively the civilization development that we observe in our day-by-day. From this reflections and considerations, we predefined that we would worked out with a test to be answered by student composing doubles, such that the students could to discuss the answers between themselves, practicing, at the same time, their argumentative capacity considering the argumentations about a proper thesis or point of view. Another premise raised was to include contemporaneous discussions in all questions of the test. Thus, the questions were not be restricted to the knowledge of a specific discipline because always would be involved some subjective discussion referring to the central paradigms of the current economic development. A significant predisposition was to pass to the student the idea of unity, that is, to be clear to the student that the various disciplines worked out along the secondary school make part of the same scientific process and that there is a relationship between them in the explanation of nature. For this purpose, the questions were presented in a single question sheet that contains a proper title without making explicit names of specific disciplines. We applied the tests for three classes simultaneously. For each group of students, it was given one hundred minutes to conclude the test. Subsequently to the application of the test, we did an analysis to verify the accuracy of the adopted methodology. Such analysis corresponded to a quantitative and a qualitative vision of the process.

In the qualitative approach, we promote a semi-structured interview with some students that did the test. In the quantitative approach, we analyze the obtained grades and we compare them with the grades that are obtained in the specific tests of the individual involved disciplines. In order to verify the accuracy of the methodology of this work, the qualitative analysis was more relevant because we detected from it the real impact under the learning of the involved students. For the determination of the mentioned qualitative data, we select a group of students considering sample statistics criteria. 97 students did the test. We utilize the appropriated statistics criteria to perform the interview just with 31 students, having a representativeness with confidence interval (or statistical confidence) of $95 \%$ and margin of error of $5 \%$. Analogously to what occurs in electoral surveys, in which is normally considered the confidence interval of $95 \%$ and an error margin error of $2 \%$, we precede some theoretical calculations to define the ideal size of the student sample to be interviewed. Since the total of students that did the test, it was not possible to reach the error margin of $2 \%$. Before we start the interview, the student's rate about their perceptions related to the experience of doing a test like what we are proposing. Considering all aspects, the students should indicate as "terrible", "bad", "regular", "good" or "great", the experience that they have in doing an interdisciplinary test like the referred in this work. The detailing about the criteria of sampling that were adopted until the determination of the students that participate of the interview are presented in the next chapter. Based on quantitative and qualitative results of this work, it was possible to identify the points that are possible to be improved for future opportunities. As well as a research about the quality of a product, is possible to utilize the opinions of the clients to promote a feedback in the methodology and improve the product. In the reality raised in the work, the clients are the students that participate of the process and the product is the developed test (Figure 1).

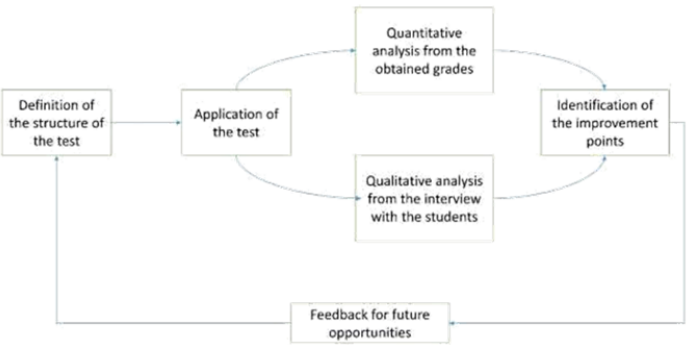

Figure I Summary of the methodology that was adopted in this work.

\section{Results and discussion}

The results of this work are built considering quantitative and qualitative data. First of all, we'll expose the results from the quantitative data. Next, we bring the qualitative results as well as the criteria that are utilized for the collection of such data. After the presentation of these data, we'll discuss how they interrelate each other so as to possibility conclusions about the methodology that is proposed in this work. After the application of the tests, we collected the grades and we made a numerical analysis that involved the determination of relevant statistics variables. The grades are measured between zero and one hundred. We also analyze the obtained grades that were obtained by the students. Table 1 shows the statistical analyzes of the grades obtained for the students. Results shown in Table 1 allow us several relevant analyses. The fact that the variation coefficient be smaller than 0.3 means that the obtained data represent well the individual data of the sample. ${ }^{6}$ Thus, we can utilize the average from Table 1 to measure the performance of the students in the test. By comparing the obtained grades in the proposed interdisciplinary test with the grades obtained from similar individual tests of the involved disciplines, we can stablish some positive analyzes about the methodology of this work. Table 2 shows the same statistics variables built on the grades obtained for the same group of students in tests of individual disciplines. These grades were extracted from tests about the same subjects that are present in our interdisciplinary test and involved the same considered group of students.

Table I Numerical results obtained through the grades of the students

\begin{tabular}{ll}
\hline Statistical parameters & Grades \\
\hline Average & 66.3 \\
Standard deviation & 14.2 \\
Median & 66.4 \\
Mode & 60 \\
Variation coefficient & 0.21 \\
\hline
\end{tabular}

From Table 2, we obtain various relevant information. We observe that the proposed interdisciplinary test was more effective when we take in consideration the result obtained for the students as well as in the representativeness of the grades obtained for the students. There 
are various discussions related to the effectiveness of the utilization of numerical grades to measure de performance of the students. ${ }^{7-9}$ More than the average obtained for a class of students, we must consider other variables that can be indicate the real representativeness of these calculated result. Table 2 show us that the interdisciplinary test applied to the students is numerically better than the individual tests of the involved disciplines which are traditionally segmented by specific subjects. Beyond the average be greater than the grades obtained in individual disciplines, the fact of we observe smaller values of standard deviations and the variation coefficient shows that the average grade

Table 2 Notas obtidas em provas de disciplinas individuais e na avaliação interdisciplinar indicated in the proposed interdisciplinary test is more representative than those that were obtained in tests about individual disciplines. In this way, the calculated average for the interdisciplinary test represent with greater fidelity the performance of a student randomly chosen in the analyzed population. In other perspective, we have a greater reliability to ensure that, among the averages presented in Table 2, the value related to the interdisciplinary test is the best to represent the student behavior. The variation coefficient, smaller than 0.3 , shows that the calculated average represent with relative fidelity the performance of the students.

\begin{tabular}{llllll}
\hline Statistical & Interdisciplinary & Physics & Chemistry & Geography & Biology \\
\hline variable & test & test & test & test & test \\
\hline Average & 66.3 & 52.6 & 22.5 & 65.4 & 60.6 \\
Standard deviation & 14.2 & 27.9 & 22 & 18.4 & 21.6 \\
Median & 66.4 & 50 & 20 & 69 & 62 \\
Mode & 60 & 60 & 0 & 74 & 80 \\
Variation coefficient & 0.21 & 0.53 & 0.98 & 0.28 & 0.36 \\
\hline
\end{tabular}

In analyzes related to the teaching aspects, the monitoring of the performance, investigated exclusively by number is not always the desirable practice. Therefore, we did a qualitative and exploratory analysis in order to determine the perceptions of the students about the proposed interdisciplinary test. Such investigation was made of a research of opinion about the experience that the interdisciplinary test provided to the student. In this step, the selected students evaluated the experience of the test as "terrible", "bad", "regular", "good" or "great". After the test, we start a semi-structured interview with the students. In order to avoid talking with all the 97 students, we adopt a sampling criterion for the selection of some students. The size of the sample is based on error margin and on the confidence interval desired. ${ }^{6}$ We determine the size of the sample considering the calculated standard deviation as reference. Considering the standard deviation of 14.2 showed in Table 2, an interval of confidence of $95 \%$, we built the Table 3, which shows the size of the sample that is necessary for each specific error margin. Table 3 was built by considering the criterion determined by Ref, 6 whose give the number of the sample for a specific standard deviation. Equation 1 shows the calculation procedure to obtain the values presented in Table 3.

Table 3 Size of the sample that is necessary for each considered error margin for the standard deviation of 14.2

\begin{tabular}{ll} 
Sample size for the $\mathbf{C l}$ of $\mathbf{9 5 \%}$ & Error margin (\%) \\
194 & 2 \\
86 & 3 \\
49 & 4 \\
31 & 5 \\
22 & 6 \\
16 & 7 \\
12 & 8 \\
10 & 9 \\
8 & 10 \\
\hline
\end{tabular}

*Confidence interval

$$
n=\left(\frac{z . \sigma}{e}\right)^{2}
$$

In Eq. (1), $z$ represents the variable obtained in the specific table of the normal distribution, $o$ represents the standard deviation of the population and $e$ represents the considered error margin. From the results showed in Table 3, we decide to consider with a sample of 31 students. Thus, we need to take less than one third of the total group of student and the qualitative analyzes containing an error margin of 5\%. Table 4 shows the answers of the students about the experience obtained through the proposed interdisciplinary test. As highlighted, the percentages contained in Table 4 are illustrated with error margins of $5 \%$ for more or less. We note that for $87 \%$ of the involved students, the experience of the interdisciplinary test was considered good or great. Only $13 \%$ of the students considered the experience as regular. After the evaluation of the students, we start the interview with small group of students. Among the three involved classes in the study, we selected ten students of two classes and eleven students of the other class. Inside each class, we select two groups of students. One composed by students with grades bellow the median e other composed by students with grades above the median. For the classes that we take ten students, we randomly chose five students bellow the median e other five above the median. For the class where we take eleven students to compose the sample interviewed, we randomly chose five students bellow the median and six above the median. The central aim of the interview was to detect the perceptions of the students about the real impact of the test in the learning of the students as well as for obtain suggestions of improvements for similar future experiences.

Table 4 Answers of the students about the experience obtained through proposed interdisciplinary test

\begin{tabular}{lll}
\hline Rate & Frequency & Percentage (\%) \\
\hline Terrible & 0 & 0 \\
Bad & 0 & 0 \\
Regular & 4 & 13 \\
Good & 21 & 68 \\
Great & 6 & 19 \\
\hline
\end{tabular}

Among the main perceptions of the students, we highlight the anxiety related by almost all students. The students related that in function of never have experienced a similar test, they were very apprehensive with the interdisciplinary test. We talk with the students about the test during 30 days, but it does not avoid the anxiety experienced by most 
part of the students. Most students related a feeling of relief when they finished the test. We consider that 30 days would be enough to aid students to control their emotions and be more prepared to answer the test, but we do not verify that. The explanation for such observation is related to the characteristics of the written tests, which are a great source of anxiety for the students, even the best prepared. A possibility to minimize the negative impacts of the anxiety would communicate the students with more than 30 days in advance and promote more moments of conversation with the students. The interview with the students led us to enquire about what could modify in the current practice to improve the experiences of the other students in future opportunities. Students demand more "conversations in group" that would consist in meetings between the teachers that would elaborate the test and each class separately. In this sense, students suggested class with more of teacher in the class. The goal of this class would be connect the subjects under considerations more clearly. Students believe that a conversation with the teachers specialized in distinct areas is a good opportunity for them to detect more easily the relationships between the various disciplines. Students stressed the importance of the class of the individual disciplines, emphasizing that the classes with more of teacher simultaneously would complement the traditional classes with just one teacher. Students said that the contents worked out separately through the traditional classes do not difficult the understanding of the test, but they also said that some moments with more than one teacher would be important in the consolidation of the contents that dialogue each other.

The students interviewed considered as positive the way that the test was built. Students were unanimous to mention the fact that, without our interdisciplinary test, would not be possible to connect the various disciplines. In other words, students emphasized that without our test, they do not would be able to see that the subject Energy could be studied under various different perspectives and these multiple visions allow connections for the understanding of the nature. Most of students mentioned that would not be able of, just by themselves, to connect the chemical reactions with the operation of an engine of a car. They also mentioned that would not be able, just by themselves, to connect the first law of Thermodynamics with the photosynthesis process observed in plants. These observations corroborate the strong current idea about the role played by the teacher during a class, that is, the creation of connections with phenomena of the visual and touchable word of the students. About such theme, a student related something quite representative: “... through this test I could note that the nature is a global process, which is not placed inside individual blocks of specific discipline... the various disciplines can be combined in order to explain the nature..." This speech shows something very significant. The scientific knowledge is segmented in different disciplines for ontological and epistemological reasons. The application of the proposed test has a great potential to aid students to finish the secondary school knowing that the science exists for the comprehension of the nature and it is segmented in disciplines in order to guarantee that such process of comprehension combine comprehensiveness and simplicity.

\section{Conclusion}

In times of great modifications in the perspectives of the relationship between teaching and learning, the role of the professor in being a link between the student and the holistic vision of the world is more demanded today. In front of innumerous teaching methodologies that modify the relationship between teaching and learning, as the active methodologies (peer instruction learning, for example), the role of the teacher in being an agent to foment the search of a unified vision of the science remains alive. Such role do not must be restricted to the classroom because it must be explored in the written tests and other evaluations of the students. In this sense, this work illustrates a possibility of to elaborate integrated written tests by means of a simple methodology and easily feasible in the day-by-day of the secondary students. The various observations cited in this work allow us to conclude that the application of proposed methodology was successfully applied because it combines quantitative and qualitative analyzes. The grades obtained by the students in the interdisciplinary test were better than those obtained when they did similar individual tests, in average terms. In addition, the small values of standard deviation and variation coefficient indicate a greater representativeness in the average calculated for the interdisciplinary test when we compare with the calculus for the individual tests. In addition, the qualitative analyzes indicate that the students considered the experience with our interdisciplinary test like good or great and through the proposed test they could to establish connections between the various sciences that describes the nature. The qualitative data that were collected in this work, suggest that the experience for the students would be better if some simple actions were done. The most significant of them that was highly signalized by the students would be meetings consisting of conversation with the students and involving more than one teacher in this moment. These conversations would be an important opportunity to relate in a more deep way the involved disciplines. Thinking in perspectives for future works, there are various possibilities that arise with the point of view considered in this work. Other areas of the scientific knowledge can be unified for the elaboration of tests like the presented in this work. In this context, the limiting factor of the process will be the creativity of the involved teachers in planning and structuring central relevant themes that englobe the greater number of contents of each involved discipline.

\section{Acknowledgements}

None.

\section{Conflict of interest}

The author declares there is no conflict of interest.

\section{References}

1. Fazenda ICA. Didática e interdisciplinaridade. Papirus Editora. 2008. p. $1-195$.

2. Lavaqui V, Batista IDL. Interdisciplinaridade em ensino de ciências e de matemática no ensino médio. Ciência \& Educação (Bauru). 2007;13(3):399-420

3. da Silva Augusto TG, de Andrade Caldeira AM. Dificuldades para a implantação de práticas interdisciplinares em escolas estaduais, apontadas por professores da área de ciências da natureza. Investigações em Ensino de Ciências. 2016;12(1):139-154.

4. Fourez G. Crise no ensino de ciências?. Investigações em ensino de ciências. 2016;8(2):109-123

5. Ward H, Roden J, Hewlett C, et al. Ensino de ciências. Artmed Editora. 2009.

6. Silvestre AL. Análise de dados e estatística descritiva. Escolar editora. 2007.

7. Assis Gomes CM. Avaliando a avaliação escolar: notas escolares e inteligência fluida. Psicologia em Estudo. 2010;15(4):1-9.

8. Daniels H. Vygotsky e a pedagogia. Edições Loyola. 2003.

9. Gatti BAO. Avaliação em sala de aula. Estudos em avaliação educacional. 2003;(27):97-114. 